\title{
Review: Bilirubin pKa studies; new models and theories indicate high pKa values in water, dimethylformamide and DMSO
}

\author{
Pasupati Mukerjee ${ }^{+1}$ and J Donald Ostrow*+2
}

\begin{abstract}
Background: Correct aqueous pKa values of unconjugated bilirubin (UCB), a poorly-soluble, unstable substance, are essential for understanding its functions. Our prior solvent partition studies, of unlabeled and $\left[{ }^{14} C\right]$ UCB, indicated pKa values above 8.0. These high values were attributed to effects of internal H-bonding in UCB. Many earlier and subsequent studies have reported lower pKa values, some even below 5.0, which are often used to describe the behavior of UCB. We here review 18 published studies that assessed aqueous pKa values of UCB, critically evaluating their methodologies in relation to essential preconditions for valid pKa measurements (short-duration experiments with purified UCB below saturation and accounting for self-association of UCB).

Results: These re-assessments identified major deficiencies that invalidate the results of all but our partition studies. New theoretical modeling of UCB titrations shows remarkable, unexpected effects of self-association, yielding falsely low pKa estimates, and provides some rationalization of the titration anomalies. The titration behavior reported for a soluble thioether conjugate of UCB at high aqueous concentrations is shown to be highly anomalous. Theoretical reinterpretations of data in DMSO and dimethylformamide show that those indirectly-derived aqueous pKa values are unacceptable, and indicate new, high average pKa values for UCB in non-aqueous media (>11 in DMSO and, probably, $>10$ in dimethylformamide).
\end{abstract}

Conclusions: No reliable aqueous pKa values of UCB are available for comparison with our partition-derived results. A companion paper shows that only the high pKa values can explain the $\mathrm{pH}$-dependence of UCB binding to phospholipids, cyclodextrins, and alkyl-glycoside and bile salt micelles.

\section{Background}

Unconjugated bilirubin (UCB) in aqueous solution exists as an equilibrium among three species, the diacid $\left(\mathrm{H}_{2} \mathrm{~B}\right)$, the monoanions $\left(\mathrm{HB}^{-}\right)$and the dianion $\left(\mathrm{B}^{-}\right)$[1]. Each species differs as to ionization states, properties and functions [1]. The fully protonated, uncharged, UCB diacid diffuses freely across lipid membranes [2,3]. The monoanion, with one ionized carboxylic group, is the main substrate for active cellular export of UCB by ABC-transporters [3]. The dianion, with two ionized - $\mathrm{COO}^{-}$groups, is reported to be bound preferentially with high affinity to

* Correspondence: jdostrow@medicine.washington.edu

2 Gl/Hepatology Division, Department of Medicine, Box 356424, University of Washington School of Medicine, 1959 NE Pacific St., Seattle, WA 98195-6424, USA

+ Contributed equally

Full list of author information is available at the end of the article serum albumin [4,5], apolipoprotein-D [6], and ligandin and other GSH-transferases [7], as well as to bile salts [8].

Since the relative proportion of the three species depends on the $\mathrm{pH}$ of the solution and the $\mathrm{pKa}$ values of UCB [1], the true pKa values of UCB are of great physiological and basic relevance. There are, however, tremendous variations among the reported pKa values for bilirubin in aqueous solutions, as determined by a wide variety of methods (table eight in Boiadjiev et al. [9]). Most studies in the literature suggested pKa values below 7.0 and even below 5.0 [9], whereas our solvent partition studies $[10,11]$ indicated that the two pKa values were much higher, 8.12 and 8.44. The variations in reported pKa estimates are due in large part to the methodological difficulties of studying UCB at concentrations below its low aqueous solubility limit $(<0.1 \mu \mathrm{M}$ at $\mathrm{pH} \leq 7.8$ [12]) and the ready degradation of the pigment to more polar 
derivatives with much higher solubility and different ionization properties [13-15].

The choice of pKa values also affects estimates of the aqueous solubility of UCB [12]. If the assumed pKa values of 4.4 and 5.0 [16] are used to represent low pKa's, the ratio of diacid/dianion at $\mathrm{pH} 7.4$ would change from 0.58 (high pKa's) to only $4 \times 10^{-6}$ (low pKa's), and the solubility of UCB diacid would change from the experimental value of $5 \times 10^{-8} \mathrm{M}$ [10] to less than $10^{-14} \mathrm{M}$ [12]. Such differences are clearly of great significance in understanding the interactions of UCB with proteins and cell membranes [1] and its protective and toxic effects on cells [3].

We have critically re-examined many conflicting accounts of the pKa data and have assessed the reliability of the methods used, in relationship to minimal criteria (detailed below) as well as other considerations. In this paper, we examine studies that reported pKa values of UCB in simple aqueous systems, pure organic solvents, or mixtures of organic and aqueous solvents (Additional File 1, Table S1). The effects of varied $\mathrm{pH}$ on the binding of UCB to phospholipids, dodecylmaltoside micelles, cyclodextrins, and bile salt micelles are considered in a companion paper [17]. Extensive reinterpretations of the published data, employing some new models, reveal that these data are compatible with the high aqueous pKa values for UCB and incompatible with low pKa values.

\section{Methods}

\section{Assessment Criteria for Validity of Studies}

By definition, $\mathrm{pKa}$ values can only be determined if the free, aqueous phase UCB concentrations are below saturation and monomeric; any UCB aggregates formed at higher concentrations must be measured and accounted for. The propensity of UCB to deteriorate requires that: the pigment is purified just before experimental use [15], it is dissolved and studied under conditions that minimize exposure to high $\mathrm{pH}$, light and oxygen, and that the measurements are made over a brief time span. These minimal criteria must be met if $\mathrm{pKa}$ determinations are to be valid.

The full criteria used in assessing such studies are: 1 ) The UCB has been purified and its purity documented by spectrometric and chromatographic methods [13]; 2) There should be no significant degradation of UCB, to polar derivatives with low pKa values, during its dissolution or storage in concentrated stock solutions, or during the incubation and analyses [13]; 3) Measurements are made after equilibrium is achieved, but the equilibrium should be attained rapidly to minimize degradation of UCB; 4) The $\mathrm{pH}$ range examined should ideally be wide enough to encompass all suggested pKa values of UCB (pH 4 to 10), and include sufficient data points for mathematical modeling; 5) Since thermodynamic theory defines $\mathrm{pKa}$ as an equilibrium among dissolved, monomeric species, the study should be done at unbound UCB concentrations below to minimally above aqueous saturation, must not be confounded by the presence of insoluble aggregates of $\mathrm{H}_{2} \mathrm{~B}$, and must include a measurement and accounting of any soluble multimers (such as $B=\mathrm{dim}$ ers) [10]. To assess the likelihood of the involvement of colloidal and coarser particles, we have calculated the supersaturation ratio, $R$, which is the free UCB concentration divided by the estimated solubility of UCB at a given $\mathrm{pH}$ (e.g. $55 \mathrm{nM}$ at $\mathrm{pH}$ 4) $[10,12] . \mathrm{R}$ is, in effect, a measure of the driving force for nucleation and growth of particles.

\section{Selection of Publications for Further Analysis}

To find papers for possible review, we electronically searched PubMed (1967-date) and ISI and Chemical Abstracts databases back to 1950, using the keywords "bilirubin, hydrogen-ion concentration, $\mathrm{pH}, \mathrm{pKa}$ ", as well as the reference lists in papers thus discovered. To locate papers published earlier than 1968, we manually searched T.K. With's two comprehensive compendia of studies related to bilirubin $[18,19]$. Papers were eliminated that dealt only with: bile pigments other than biladienes, bilirubin ester conjugates, or effects of $\mathrm{pH}$ on binding of UCB to other molecules. We then selected all papers that derived $\mathrm{pKa}$ values from their data and met the majority of the criteria of validity summarized above, plus others that did not, but are frequently quoted (see table eight in Boiadjiev et al. [9]) and therefore required comment.

Additional File 1, Table S1 lists and summarizes the 18 studies and indicates the experimental limitations of each study. Of these 18 studies: four utilized spectrometric titration of highly supersaturated solutions of UCB [2023]; two used potentiometric titration of supersaturated solutions of UCB [16,24] (the former [16] also assumed low pKa values to model the data, the other included Triton-X100 detergent in the system); one performed potentiometric titration of a water-soluble, thioether conjugate of polyethylene glycol monomethyl ether with UCB (MPEG-S-BR) [9]; two studied UCB crystal dissolution vs. $\mathrm{pH}[22,25]$ (the problems of such inherently supersaturated systems are discussed in Hahm, et al. [10]); two derived aqueous $\mathrm{pKa}$ values from studies of UCB in dimethylformamide (DMF) [26] or DMSO [27]; four studied $\left[{ }^{13} \mathrm{C}\right]$-labeled mesobilirubin-XIII $\alpha$ in mixed solvent systems of DMSO and water [28-31]; and three measured solvent partition of UCB between an organic solvent phase and water over a range $\mathrm{pH}$ values $[10,11,32]$ (the earliest [32] used systems very supersaturated with UCB at all $\mathrm{pH}$ values and assumed low $\mathrm{pKa}$ values to model the data). 


\section{Results and Discussion}

\section{Studies of UCB in Simple Aqueous Systems Spectroscopic Titrations}

Spectral changes have been reported when aqueous solutions of bilirubin at high $\mathrm{pH}$ are acidified rapidly [33,34] or gradually [35]. Formation of colloidal aggregates and coarser particles from supersaturated solutions can produce spectral changes similar to those produced by acidification and may vary with aging [33,34]. Such variability is to be expected because of kinetic control of processes such as homogeneous or heterogeneous nucleation, and growth and flocculation of colloidal particles [36]

At $0.3 \mu \mathrm{M}$, with by far the lowest $\mathrm{R}$ value of 5.5 at $\mathrm{pH}$ 7.0, Hansen et al. [27] reported that there was no immediate spectral change as $\mathrm{pH}$ was varied from 9 to 7 , but light scattering increased over 30 minutes at $\mathrm{pH}$ 7. At higher UCB concentrations, however, they observed spectral changes, accompanied by an increase in light scattering, as pH fell from 8 and 7. Lee and Gartner [34] worked at the modestly higher $\mathrm{R}$ of 15.5 at pH 7.0, in the presence of the antioxidants, ascorbate and EDTA. As pH increased, they observed a relatively steep sigmoidal increase in $\mathrm{A}_{440}$ of $\mathrm{UCB}$ in phosphate buffer, with a titration midpoint at $\mathrm{pH} \sim 7.5$. These investigators did not derive any $\mathrm{pKa}$ values from the titration midpoint. Using a much more saturated system (R 275), Gray et al. [20] reported that the absorbance of $\mathrm{UCB}$ at the band maximum decreased as $\mathrm{pH}$ fell from 8 to 6 , and they estimated the average $\mathrm{pKa}$ to be about 7.1. These variable spectral changes are consistent with formation of colloidal or coarser particles [27,33,34].

At a concentration of $1.4 \mu \mathrm{M}(\mathrm{R}=25)$, Moroi et al. [22] estimated a $\mathrm{pKa}_{2}$ value of 7.3-7.6 and a $\mathrm{pKa}_{1}$ of 6.1-6.5. Russell et al. studied changes in the vibrational (resonance Raman) and electronic (UV-Visible) spectra of UCB [23]. On lowering the pH from 10.0 to 7.4 in aque-

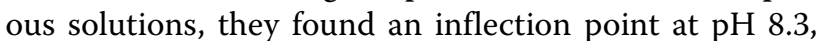
and deduced a high $\mathrm{pKa}_{2}$ value of 8.3. They reported also that "Under these conditions the titration was reversible and no precipitation was observed. This was confirmed by comparing spectra obtained before and after filtration." However, while stable supersaturation is possible, its relief leading to phase separation may not lead to particles large enough to be removed by ordinary filtration [12]. At lower $\mathrm{pH}$ values, the authors found that precipitation occurred. They estimated an approximate value of about 6 for $\mathrm{pKa}_{1}$.

Kolosov and Shapovalenko [21], in a paper lacking many experimental details, reported that absorbance at $430 \mathrm{~nm}$ decreased by about $31 \%$ as $\mathrm{pH}$ decreased from 8.5 to 6.5 and by about $15 \%$ as $\mathrm{pH}$ decreased from 5.5 to 4.5. Three sets of $\mathrm{pKa}$ values were invoked, 5.2 for $\mathrm{pKa}_{1}$, 5.9 for $\mathrm{pKa}_{2}$ and 7.3 for the average of $\mathrm{pKa}_{3}$ and $\mathrm{pKa}_{4}$.
These latter $\mathrm{pKa}$ values would suggest that bilirubin exists primarily as a tetra-anion at $\mathrm{pH} 8$, an unlikely possibility [27]. Recent authors [37] noted these low $\mathrm{pKa}_{1}$ and $\mathrm{pKa}_{2}$ values, but did not mention the $\mathrm{pKa}_{3}$ and $\mathrm{pKa}_{4}$ values obtained from the same titration.

In summary, spectroscopic titrations in water at $\mathrm{pH} 8$ or below have yielded a wide range of estimated pKa values (Additional File 1, Table S1), but none have been carried out both with purified UCB and in undersaturated solutions. The spectral changes observed were likely due mainly to the formation of colloids and coarser aggregates, and are therefore not relevant to, or valid for, estimation of $\mathrm{pKa}$ values in an undersaturated solution of UCB monomers.

\section{Potentiometric Titrations}

In an early study, Overbeek et al. [16] dissolved a UCB suspension by adding $\mathrm{NaOH}$, then performed a potentiometric titration with $\mathrm{HCl}$, followed by a backtitration with $\mathrm{NaOH}$. In order to interpret their titrations, they assumed $\mathrm{pKa}_{1}$ and $\mathrm{pKa}_{2}$ values of 4.4 and 5.0. Lucassen [38] encountered serious difficulties in trying to reproduce these experiments of Overbeek et al. Krasner and Yaffe [24] reported a pKa value of 7.55 from potentiometric titrations with both $\mathrm{HCl}$ and $\mathrm{NaOH}$. Hansen et al. [27] obtained very similar titration curves. Because of massive supersaturation and extensive precipitation, however, no reliable pKa values can be derived from these titrations, as emphasized by Hansen et al. [27], Lee et al. [26], and Carey [35].

\section{Solubility vs. $\mathrm{pH}$}

Ostrow et al. [25] studied the dissolution of UCB crystals in buffers. They found that stable UCB concentrations were achieved only after 48 hours and varied little over the $\mathrm{pH}$ range 4 to 6 . Modeling the data yielded $\mathrm{pKa}_{1}$ and $\mathrm{pKa}_{2}$ of 6.8 and 9.3 with a high average pKa of 8.1. They pointed out some sources of uncertainties, particularly in the estimate of the low solubility of uncharged bilirubin diacid. This was also noted as a major problem by Moroi et al. [22], who thought that their estimate of $\mathrm{pKa}_{2}$ from solubility data, 7.6, was more reliable than their estimate of $\mathrm{pKa}_{1}, 6.0$. Subsequently, the numerous difficulties of the solubility method, arising out of crystal imperfections, fine particle solubility effects, difficulty of equilibration and Ostwald ripening, have been discussed theoretically and documented experimentally [10]. These problems render doubtful the validity of such estimates of pKa values.

\section{Bilirubin in Systems Containing Organic Solvents}

To circumvent the problems created by the low aqueous solubility of UCB, several investigators have attempted to indirectly estimate $\mathrm{pKa}$ values in water from titrations in organic solvents in which the solubility of UCB is high, 
dimethylformamide (DMF) [26] and DMSO [27]. Neither of these studies, however, involved any direct measurements in water. As mentioned below, DMSO-water mixtures have also been used [29,37].

\section{Titrations in DMF}

A seldom-used method, of estimating pKa values in water from measurements of half-neutralization potentials (HNPs) in an organic solvent, was applied by Lee $e t$ al. [26] to UCB in DMF. The difference in $\mathrm{HNP}_{1}$, corresponding roughly to $\mathrm{pKa}_{1}$ in DMF, from the HNP of benzoic acid, $\Delta \mathrm{HNP}_{1}$, was found to be linearly related to $\mathrm{pKa}_{1}$ values in water of four reference dibasic acids, succinic, glutaric, adipic, and azelaic. Using this reference curve, the measured $\triangle \mathrm{HNP}_{1}$ for UCB in DMF was used to estimate its $\mathrm{pKa}_{1}$ in water. Similarly, the difference between $\mathrm{HNP}_{2}$ (corresponding to $\mathrm{pKa}_{2}$ ) and $\mathrm{HNP}_{1}$ for $\mathrm{UCB}$ in DMF was related to the difference of $\mathrm{pKa}_{2}-\mathrm{pKa}_{1}$ for the reference acids, leading to the estimate of $\mathrm{pKa}_{2}-\mathrm{pKa}_{1}$ of $\mathrm{UCB}$ in water from the measured $\mathrm{HNP}_{2}-\mathrm{HNP}_{1}$ measured in DMF. This method yielded low values of 4.3 for $\mathrm{pKa}_{1}$ and 5.3 for $\mathrm{pKa}_{2}$ for UCB in water [26].

This indirect approach is based on some rough correlations reported in 1958 by Streuli and Miron [39], who measured $\mathrm{HNP}_{1}$ values for 44 carboxylic acids in pyridine. They reported three very different groups of correlations of $\mathrm{HNP}_{1}$ with aqueous $\mathrm{pKa}$ values and numerous deviations from each of them, particularly for acids with intramolecular hydrogen bonding. Ortho-hydroxybenzoic acid, for example, deviated from the correlation line of other ortho-substituted benzoic acids by $1.5 \mathrm{pKa}$ units. From the correlation line between $\mathrm{HNP}_{1}$ and six dicarboxylic acids similar to the four used by Lee et al. [26], maleic and phthalic acids differed by 1.8 and 0.9 units respectively. Similarly, maleic acid showed a deviation of 2.9 units from the correlation of $\mathrm{HNP}_{2}-\mathrm{HNP}_{1}$ with $\mathrm{pKa}_{2}-$ $\mathrm{pKa}_{1}$ of the reference dibasic acids. Maleic acid, with such high discrepancies, has only one intramolecular H-bond in the monoanion, whereas uncharged UCB diacid has six such bonds. We believe that deviations caused by the complex intramolecular hydrogen bonding of UCB cannot be easily evaluated or ignored, and that this highly indirect $\triangle$ HNP method, demonstrably unreliable for estimating pKa values of simple acids in water, is unlikely to be reliable for a molecule as complex as UCB. In DMF, $\triangle \mathrm{HNP}_{1}$ for UCB is closest to that of succinic acid, for which Kolthoff et al. [40] had directly measured very high $\mathrm{pKa}_{1}$ and $\mathrm{pKa}_{2}$ values in DMF of 10.05 and 17.21, respectively. Therefore, pKa values of UCB in DMF are probably higher than 10.05 and thus considerably higher than our partition-derived values of 8.12 and 8.44 for UCB in water [10]. This is in keeping with the observation that
pKa values of carboxylic acids are higher in DMF than in water [41].

\section{Titrations in DMSO}

Based on extrapolation to $0 \%$ DMSO from $\left[{ }^{13} \mathrm{C}\right]-\mathrm{NMR}$ measurements of $-\left[{ }^{13} \mathrm{C}\right] \mathrm{OOH}$ group ionizations of mesobilirubin in varied mixtures of DMSO and water, the two $\mathrm{pKa}$ values of mesobilirubin in water have been reported to be 4.2 and $4.9[9,29,30,37]$. Due to the demonstrated problems of insolubility [12], large errors in $\mathrm{pH}$ measurements in the mixed solvents [31,42], and the long, even overnight duration of the $\left[{ }^{13} \mathrm{C}\right]-\mathrm{NMR}$ analyses [29], these studies are not interpretable.

Hansen et al. [27] estimated an average pKa value of 4.4 for UCB in aqueous solutions from comparison of titrations of UCB and m-hydroxybenzoic acid performed in DMSO. Using the Born equation [27], assuming that all ions are spherical, and arbitrarily setting the radii of bilirubin IX $\alpha, \mathrm{m}$-hydroxybenzoic acid, and the solvated proton to be 7,2 , and $2 \AA$, respectively, they calculated the pKa of m-hydroxybenzoic acid in DMSO to be 5.1 from its known aqueous pKa value of 4.0 [27]. Since "Potentiometric cotitration of bilirubin and m-hydroxybenzoic acid revealed that the carboxylic acid pKa's of bilirubin and $\mathrm{m}$-hydroxybenzoic acid are identical in dimethyl sulfoxide within experimental error ...", the pKa of UCB in DMSO was estimated to be 5.1 also. The Born equation was then used to calculate the average pKa of UCB in water to be 4.4. It is well-known that the acid-base character of solvents and several other factors are of much greater importance in determining pKa values than the purely electrostatic interactions of spherical ions covered by the Born equation $[41,43]$. Indeed, the directly measured pKa value of m-hydroxybenzoic acid in DMSO is 11.1, [44], which is 6 units higher than the value of 5.1 calculated by Hansen et al. some years later [27]. Benzoic acid and $m$-methyl benzoic acid have a similar pKa of 11.0 in DMSO [44]. The indisputable experimental identity of pKa values of m-hydroxybenzoic acid and UCB in DMSO thus leads to a firm conclusion that the average pKa of UCB in DMSO is about 11.1, which is notably about 3 units higher than the average pKa of 8.3 in water, derived from our partition studies [10]. This is consistent with the finding that carboxylic acids of many kinds have higher pKa values in DMSO than in water [41]. Therefore, the low estimate of 5.1 for the average pKa of UCB in DMSO, and the estimated average pKa of UCB in water of 4.4, calculated therefrom by use of the Born equation and arbitrarily chosen radii of the ions, are both unacceptable. We apologize for having accepted this erroneous value in the past [25], because we paid insufficient attention to the earlier work of Kolthoff et al. [44].

There are large but variable solvent effects associated with molecules in which H-bonds donated by carboxyl groups are broken on ionization (i.e. the second dissocia- 
tion of dicarboxylic malonic or maleic acids) and with molecules such as salicylic acid, in which neighboring non-carboxylic groups donate $\mathrm{H}$-bonds to a carboxyl group [41]. Uncharged UCB diacid has a unique, complex combination of $\mathrm{H}$-bonds donated by and accepted by its carboxyl groups [1], and no simple molecular analogue is available. A quantitative interpretation of the relative $\mathrm{pKa}$ values in water and DMSO is, therefore, not feasible currently.

\section{Solvent Partition}

Irollo et al. [32] studied the variation with $\mathrm{pH}$ of the partition of unpurified UCB from Tris-buffered water into varied mixtures of unpurified methyl-isobutyl ketone and n-heptane. As summarized in Additional file 1, Table S1, this study failed to meet many of the essential criteria of validity. Most importantly, the aqueous phase was supersaturated with $\mathrm{UCB}$ throughout the narrow $\mathrm{pH}$ range (7.6-9.0) studied ( $\mathrm{R}$ was above 50 at $\mathrm{pH}$ 7.6), often with formation of visible precipitates. No pKa value can be derived from this data; indeed the authors modeled the data by assuming pKa values of 4.3 and 5.3 [26]

Our complimentary studies of solvent partition (from chlorofom into water) with unlabeled [10] and $\left[{ }^{14} \mathrm{C}\right]-\mathrm{UCB}$ [11] are the only studies to have been performed with highly purified UCB at concentrations uniformly below its solubility limits at all $\mathrm{pH}$ values. The concordance of results between the two studies refute criticisms [37] that the diazo-based assays of unlabeled UCB in the first study were inaccurate, insensitive, or non-specific for UCB. In both studies, degradation of UCB was minimized by performing the partitions rapidly, in the dark, under an argon atmosphere. The partitions utilized highly purified water, with chloroform that had been properly washed and stored to eliminate oxidative species that could rapidly degrade UCB $[45,46]$. Achievement of equilibrium was documented by reverse partitions from water into chloroform [10], and by performance of serial partitions to a constant partition ratio [11]. The constancy of the partition ratios at a given $\mathrm{pH}$ over a wide range of concentrations excluded significant aggregation of UCB diacid in the chloroform phase, and the model used took into account the self-association of the UCB dianion in the aqueous phase at high $\mathrm{pH}$ values [10]. Finally, the partitions were done over a pH range from 4 to 10 , encompassing the entire range of proposed $\mathrm{pKa}$ values from the literature. These studies thus fulfilled all the key criteria, outlined above, for a valid evaluation of the aqueous pKa values of UCB.

\section{Water-Soluble Conjugates of Bilirubin and Dicarboxylic Fatty Acids with Polyethylene Glycol Monomethyl Ether (MPEG)}

Boiadjiev et al. [9] performed $\mathrm{NaOH}$ titrations on a water-soluble conjugate of bilirubin (MPEG-S-BR), pre- pared by linking the exo-vinyl group of UCB through a thioether bridge to MPEG (average Mol. Wt. $=1900$, a 42-mer). NMR data of UCB and MPEG-S-BR dissolved in $\left(\mathrm{CD}_{3}\right)_{2} \mathrm{SO}$ and $\mathrm{CDCl}_{3}$, suggested that "the presence of the pendant polymer does not disrupt the stabilizing network of six intramolecular hydrogen bonds" in UCB. The titration with $\mathrm{NaOH}$ of MPEG-S-BR at a high nominal concentration of $8 \mathrm{mM}$ in water showed a pH value of 6.42 at the midpoint of the titration. This apparent average pKa value is midway between the average of the low $\mathrm{pKa}$ values, 4.55 [9] and that of the high pKa values, 8.28 [10]. UCB is known to be highly aggregated at such a high concentration $[9,10,47]$. Carey and Koretsky concluded that, at $\mathrm{pH} 10,270 \mu \mathrm{M} \mathrm{UCB}$ is present mostly as multimers, including mixed aggregates of $\mathrm{B}^{=}$and $\mathrm{HB}^{-}$[47]. Boiadjiev et al. [9] were unable to detect $\left[{ }^{13} \mathrm{C}\right]-$ or $\left[{ }^{1} \mathrm{H}\right]-\mathrm{NMR}$ signals from the bilirubin moiety of MPEG-S-BR dissolved in $\mathrm{D}_{2} \mathrm{O}$. This was attributed to self-association of MPEG$\mathrm{S}$-BR into large micellar aggregates [9]. Clearly, the apparent $\mathrm{pKa}$ values from the midpoint of the titration curve cannot represent the pKa of monomeric UCB. There is also no direct evidence that monomeric UCB and monomeric MPEG-S-BR have identical intramolecular $\mathrm{H}$ bonds in water.

Boiadjiev et al. [9] argued that the apparent average pKa of 6.42 for MPEG-S-BR provides evidence for the low $\mathrm{pKa}$ values of UCB by comparing the titration of MPEG-S-BR to the titrations of some water-soluble MPEG monoesters of dicarboxylic fatty acids, MPEG-FAs $=$ MPEG-OCO- $\left(\mathrm{CH}_{2}\right)_{\mathrm{n}}-\mathrm{COOH}(\mathrm{n}=2,6,11,14$ or 18$)$. The long-chain MPEG-FAs, which are expected to show extensive micelle-type aggregation, were proposed as reference models for MPEG-S-BR. We provide some arguments and evidence indicating that the MPEG-FAs are poor models for MPEG-S-BR.

In aqueous solutions, relatively hydrophobic, amphipathic molecules of different structures follow very different patterns of self-association [48-50]. Classical amphipaths, such as sodium dodecyl sulfate or sodium laurate, have flexible aliphatic chains, which can form the liquid cores of micelle-type aggregates, the polar groups remaining at the surface [51]. The self-association is highly co-operative $[48,51]$, resulting in the phenomenon of a critical micellization concentration (c.m.c.) [52]. In sharp contrast, rigid, planar, aromatic molecules such as methylene blue, which cannot form liquid-like cores in aggregates, show extensive self-association of the stacking type, with little co-operativity and, therefore, no c.m.c. $[48,53,54]$. Flexible-chain detergent-type molecules are thus very poor models for rigid, planar molecules, and are not even good models for bile salts, which have alicyclic, rigid structures $[49,50]$. UCB, depending upon the relative dispositions of the two dipyrrolic halves of the 
molecule, can have many conformations [55]. Different conformations, and ranges of conformations and shapes, may be expected for the $\mathrm{H}_{2} \mathrm{~B}, \mathrm{HB}^{-}$and $\mathrm{B}^{=}$species, and their corresponding MPEG-S-derivatives. The longer chain MPEG-FAs containing flexible aliphatic chains should resemble detergent-like amphipaths. MPEG-S-BR is unlikely to do so any more than methylene blue $[48,53]$.

The unusual characteristics of the $\mathrm{H}_{2} \mathrm{~B}, \mathrm{HB}^{-}$or $\mathrm{B}^{=}$species are displayed by their uptake into the hydrophobic environment of the anionic bile salt micelles in $50 \mathrm{mM}$ sodium taurocholate $(\mathrm{NaTC})[8,56]$. Charge effects render interactions of anions (A-) with such aggregates less favorable than the ordinary acid (HA), as is usually observed (e.g. fatty acids with cholate [57]). The micellewater distribution ratios in $50 \mathrm{mM} \mathrm{NaTC}$ of $\mathrm{H}_{2} \mathrm{~B}, \mathrm{HB}^{-}$or $B=\left(D_{0}, D_{1}\right.$ and $D_{2}$, respectively), have increasing values, however, with increasing ionization (1.4 for $\mathrm{H}_{2} \mathrm{~B}, 13$ for $\mathrm{HB}^{-}$and 730 for $\left.\mathrm{B}^{=}\right)$[8]. The increasing charge repulsions expected in the NaTC micelles must thus be more than compensated by an increasing expression of hydrophobicity $\left(\mathrm{H}_{2} \mathrm{~B}<\mathrm{HB}^{-}<\mathrm{B}^{-}\right)$. If the acid dissociation constants of $\mathrm{H}_{2} \mathrm{~B}$ and $\mathrm{HB}^{-}$are $\mathrm{K}_{1}^{\prime}$ and $\mathrm{K}_{2}^{\prime}$ in the micellized state and $K_{1}$ and $K_{2}$ in aqueous solution, it is easily shown from the schemes presented [56-58] that $\mathrm{K}_{1}^{\prime} / \mathrm{K}_{1}=\mathrm{D}_{1} / \mathrm{D}_{0}$ and $\mathrm{K}_{2} / \mathrm{K}_{2}$ $=\mathrm{D}_{2} / \mathrm{D}_{1}$. Thus, for UCB, $\mathrm{D}_{1}>\mathrm{D}_{0}, \mathrm{~K}_{1}^{\prime}>\mathrm{K}_{1}$ and $\mathrm{pK}_{1}^{\prime}<\mathrm{pK}_{1}$; similarly, $\mathrm{pK}_{2}^{\prime}<\mathrm{pK}_{2}$. The average pKa values of $\mathrm{UCB}$ in 50 $\mathrm{mM}$ NaTC aggregates are in the range of 6 to $7[8,17,57]$. These indicate that the pKa values of UCB in water, must be higher and not lower, as has been claimed [57]. This is more fully discussed in our companion paper [17]. The extraordinary increase in hydrophobic interactions with increasing ionization of UCB is also in accord with the extensive self-association displayed by UCB at high $\mathrm{pH}$, where the $B=$ dianion predominates $[9,10,47]$. Some remarkable differences we have noted in the titration curves reported for MPEG-S-BR and the long-chain MPEG-FA derivatives [9] can be rationalized on this basis, as shown below.

The long-chain MPEG-FAs are expected to produce micelle-like aggregates, for which a general equation dealing with charge effects on $\mathrm{pKa}_{(\mathrm{s})}(\mathrm{pKa}$ of an acid group at the micellar interface) [59] can be adapted:

$$
\mathrm{PKa}_{(\mathrm{s})}=\mathrm{pK}_{\mathrm{i}(\mathrm{s})}+|y| / 59.1
$$

Here, the $\mathrm{pKa}_{(\mathrm{s})}$ at $25^{\circ} \mathrm{C}$, is determined by the absolute value of the electrostatic potential $|\psi|$ at the micellar interface, expressed in millivolts, and $\mathrm{pK}_{\mathrm{i}(\mathrm{s})}$, the intrinsic $\mathrm{pK}_{(\mathrm{s})}$ value when charge effects are absent $(|\psi|=0)$. An approximate estimate of $|\psi|$ at $25^{\circ} \mathrm{C}$ when counterions are monovalent (e.g. $\left.\mathrm{Na}^{+}\right)$, can be obtained from the Gouy-
Chapman theory of electrical double layers [60] by using Equation 2.

$$
|y|(\text { in } \mathrm{mV})=51.3 \sinh ^{-1}(137 / \mathrm{A} \sqrt{\mathrm{c}})
$$

where $\mathrm{A}$ is the area at the interface in sq. $\AA$ /charge and $\mathrm{C}$ is the molar concentration of the counterions. Equations 1 and 2 show that, with increasing neutralization with $\mathrm{NaOH}$, as progressive ionization of the $-\mathrm{COOH}$ groups increases the charge density (surface potential) at the micellar-aqueous interface [59], the value of $\mathrm{A}$ decreases and the values of $|\psi|$ (Equation 2) and $\mathrm{pKa}_{(\mathrm{s})}$ (Equation 1) should increase.

Only rather qualitative applications of Equations 1 and 2 are possible here. The titration curves of the MPEGFAs [9], show some anomalous features. The expected $\mathrm{pH}$ values of 11.0-11.1, calculated from the excess $\mathrm{NaOH}$ added beyond the identified neutralization points, are 1.4-1.6 units higher than the measured $\mathrm{pH}$ values, read from the graphs. This suggests incomplete neutralization. In addition, inappropriately high molecular weights of the MPEG-FA derivatives are calculated from the $\mathrm{NaOH}$ equivalents at the assumed titration end-points and the initial weighed amounts of each derivative. Thus, from the mol. wt. of MPEG used, about 1900, the mol. wts. of the esters should be below 2300. The values calculated from the titration equivalents are much higher for the suberic, brassylic, thapsic and eicosanedioic derivatives (4633, 6866, 3969 and 5270 respectively). This indicates also ill-defined preparations and/or premature assignment of titration end-points. The calculations below are thus of qualitative significance only.

Using the published titration curves for MPEG-FA in Figure three of Boiadjiev, et al. [9]) the overall apparent pKa values of the MPEG-FA at differing degrees of neutralization can be calculated from the $\mathrm{pH}$ values read off the graph and the estimated $[\mathrm{A} /] /[\mathrm{HA}]$ ratios. These apparent $\mathrm{pKa}$ values show the trends, expected from Equations 1 and 2, to increase with progressive neutralization and charge build-up in the micelles. For the brassylic, thapsic and eicosanedioic acid derivatives respectively, the apparent pKa values are 5.0, 5.2 and 5.5 at $5 \%$ neutralization, $5.26,5.94$ and 6.60 at $50 \%$ neutralization, and 6.2, 6.5 and 7.4 at $95 \%$ neutralization. In the absence of detailed information about the free monomer concentrations, aggregate structures, and A values, quantitative calculations using Equation 2 are not possible. If we make the simplifying assumptions of complete aggregation and 60 sq. $\AA$ /charge at full neutralization, the value appropriate for dodecyl sulfate micelles [61], and assuming $\mathrm{pK}_{\mathrm{i}(\mathrm{s})}$ of 4.6, the pKa value of MPEG-O-succinate, we calculate $\mathrm{pK}_{(\mathrm{s})}$ values of $7.1,8.2$ and 8.6 at $5 \%, 50 \%$ and 95\% neutralization for MPEG-O-eicosanedioate. This 
agrees in trend and order of magnitude with the corresponding $\mathrm{pK}_{(\mathrm{s})}$ values of 5.5, 6.6 and 7.4 estimated from the experimental data. The titration curves of the flexible chain MPEG-S-FA systems thus appear to be well within the bounds expected from well-established theories of charge effects in interfacial systems. This, however, is not the case for the MPEG-S-BR titration curves, as shown below.

For a dibasic acid such as $\mathrm{UCB}$, the $\mathrm{pH}$ and $\mathrm{Na}^{+}$concentrations at any point on the titration curve can be used to calculate the apparent average $\mathrm{K}_{1}$ and $\mathrm{K}_{2}$ values, using two equations:

$$
\text { Total UCB }=\left[\mathrm{H}_{2} \mathrm{~B}\right]+\left[\mathrm{HB}^{-}\right]+\left[\mathrm{B}^{=}\right]=\left[\mathrm{H}_{2} \mathrm{~B}\right]\left(1+\mathrm{K}_{1} /\left[\mathrm{H}^{+}\right]+\mathrm{K}_{1} \mathrm{~K}_{2}\right.
$$$$
\left[\mathrm{Na}^{+}\right]=\left[\mathrm{HB}^{-}\right]+2\left[\mathrm{~B}^{=}\right]=\left[\mathrm{H}_{2} \mathrm{~B}\right]\left(\mathrm{K}_{1} /\left[\mathrm{H}^{+}\right]+2 \mathrm{~K}_{1} \mathrm{~K}_{2} /\right.
$$

The extremely minor contributions of $\left[\mathrm{H}^{+}\right]$and $\left[\mathrm{OH}^{-}\right]$ in the charge balance Equation 4 can generally be ignored. If we make the reasonable assumption that $\mathrm{K}_{1}=$ $4 \mathrm{~K}_{2}$ [41,43], simultaneous Equations 3 and 4 can be readily solved for either $\mathrm{K}_{1}$ or $\mathrm{K}_{2}$. From the estimated $\mathrm{pH}$ and $\left[\mathrm{Na}^{+}\right]$at $5 \%$ and $95 \%$ neutralization of MPEG-S-BR with $\mathrm{NaOH}$ [9], we calculate $\mathrm{pK}_{1}$ and $\mathrm{pK}_{2}$ values of 6.1 and 6.7 at $5 \%$ neutralization and very similar values of 5.9 and 6.5 at $95 \%$ neutralization, the estimation uncertainties being about 0.2 . From $5 \%$ to $95 \%$ neutralization, the charge per molecule increases by 0.9 for the monobasic MPEG-Oeicosanedioate, and the apparent $\mathrm{pKa}$ increases by 1.9 units (see above). In the case of MPEG-S-BR, a dibasic acid, the charge increases by twice as much, 1.8 units per molecule, and yet there is almost no change in pKa values. The charge effects on pKa values of MPEG-S-BR are clearly inconsistent with the micelle model.

The reverse titration of the salt of MPEG-S-BR with $\mathrm{HCl}$ reveals another remarkable inconsistency with the $\mathrm{NaOH}$ titration. The $\mathrm{pH}$ value at $5 \%$ titration (i.e. $95 \%$ neutralization) is about 10.1 , leading to a $\mathrm{pK}_{2}$ estimate of about 9.1, a very high value. In this titration, a gentle reduction in $\mathrm{pH}$ with the initial addition of $\mathrm{HCl}$ is followed by a precipitous decrease in $\mathrm{pH}$ with an inflection point, well into the titration, but before the midpoint. No such behavior is reported with the titration of MPEG-SBR with $\mathrm{NaOH}$.

Acid-base equivalences calculated from the titration data for MPEG-S-BR are also remarkable. The amount of MPEG-S-BR used in the $\mathrm{NaOH}$ titration, using the mol. wt. of 2520 given for MPEG-S-BR [9], corresponds to $0.400 \mathrm{mEq}$. Only $0.305 \mathrm{mEq}$ of $\mathrm{NaOH}$ (24\% less) was added at the assumed titration end-point. Further addition of about $0.64 \mathrm{mEq}$ of $\mathrm{NaOH}$ raised the $\mathrm{pH}$ to only
10.5, compared to the $\mathrm{pH}$ of 11.0 expected from addition of the base to a fully neutralized solution at the assumed endpoint. This indicates that there was incomplete neutralization at the assumed end-point and/or significant problems with homogeneity and purity. The back-titration of the salt of MPEG-S-BR with $\mathrm{HCl}$ used $0.345 \mathrm{mEq}$, which is $13 \%$ higher than the $0.305 \mathrm{mEq}$ of $\mathrm{NaOH}$ used for the titration of the acid, and 14\% lower than the calculated initial amount $(0.400 \mathrm{mEq})$. These discrepancies are much too large for simple acid-base titration experiments. These serious inconsistencies in the titration data for MPEG-S-BR and their dissimilarity with such data for MPEG-O-eicosanedioate, and similar amphipaths with flexible aliphatic chains, render questionable an assumption that these hydrophobic solutes behave similarly when aggregated. Thus, any conclusion about the pKa values of monomeric UCB derived from the $\mathrm{pH}$ of the midpoint of the titration of MPEG-S-BR with $\mathrm{NaOH}$ is also questionable.

In order to shed some light on the apparently anomalous titration behavior of MPEG-S-BR, we examine now some possible consequences of what is known qualitatively about the self-association of UCB to the titration behavior of MPEG-S-BR, making the simplifying assumption that it behaves like UCB. For four different models of self-aggregation of the UCB dianion, we calculated the $\mathrm{pH}$ values expected from titration of UCB with $\mathrm{NaOH}$ at concentrations similar to those used for MPEGS-BR by Boiadjiev et al. [9]. $\mathrm{pH}$ values were calculated using the assumptions and equations presented in the Appendix, and are plotted against $\mathrm{F}$, the ratio of the equivalents of added $\mathrm{NaOH}$ to the equivalents of UCB. The equivalence point corresponds to $\mathrm{F}=1$. We have used our previous estimates for $\mathrm{UCB}$ of $\mathrm{pKa}_{1}=8.1, \mathrm{pKa}_{2}=$ 8.4, and $\mathrm{K}_{\mathrm{D}}=2.6 \times 10^{5} \mathrm{M}^{-1}$, the formation constant for the dimer of $B=[10]$. Although extensive multimerization of UCB has also been indicated [9,47], the multimers have not been characterized. We have, therefore, assumed the formation of only some multimers, strictly for qualitative modeling.

Figure $1 \mathrm{~A} \& \mathrm{~B}$ shows the calculated titration curves. If there is no self-association (curve $\mathrm{A}$ ), the $\mathrm{pH}$ at the midpoint, 8.25 , is expected when $\mathrm{pKa}_{1}$ and $\mathrm{pKa}_{2}$ are 8.1 and 8.4. When the only aggregate is $\left(\mathrm{B}^{-}\right)_{2}$, the titration occurs at lower $\mathrm{pH}$ values and the midpoint $\mathrm{pH}$ is lowered quite significantly to 7.52 (curve B). For curve $\mathrm{C}$, we use a dimer-pentamer model, the added pentamer species, $(B=)_{5}$, having a formation constant $K_{5}$, given by $\log K_{5}=$ 21.66 for the equilibrium $5 \mathrm{~B}^{=}<-->\left(\mathrm{B}^{=}\right)_{5}$. The midpoint $\mathrm{pH}$ is depressed further, to 6.99 , approaching the value of 6.42 estimated for the titration of MPEG-S-BR with $\mathrm{NaOH}$ [9]. As noted above, in the real system, higher multimers of $\mathrm{B}^{=}$and mixed aggregates of $\mathrm{HB}^{-}$and $\mathrm{B}^{=}$ 

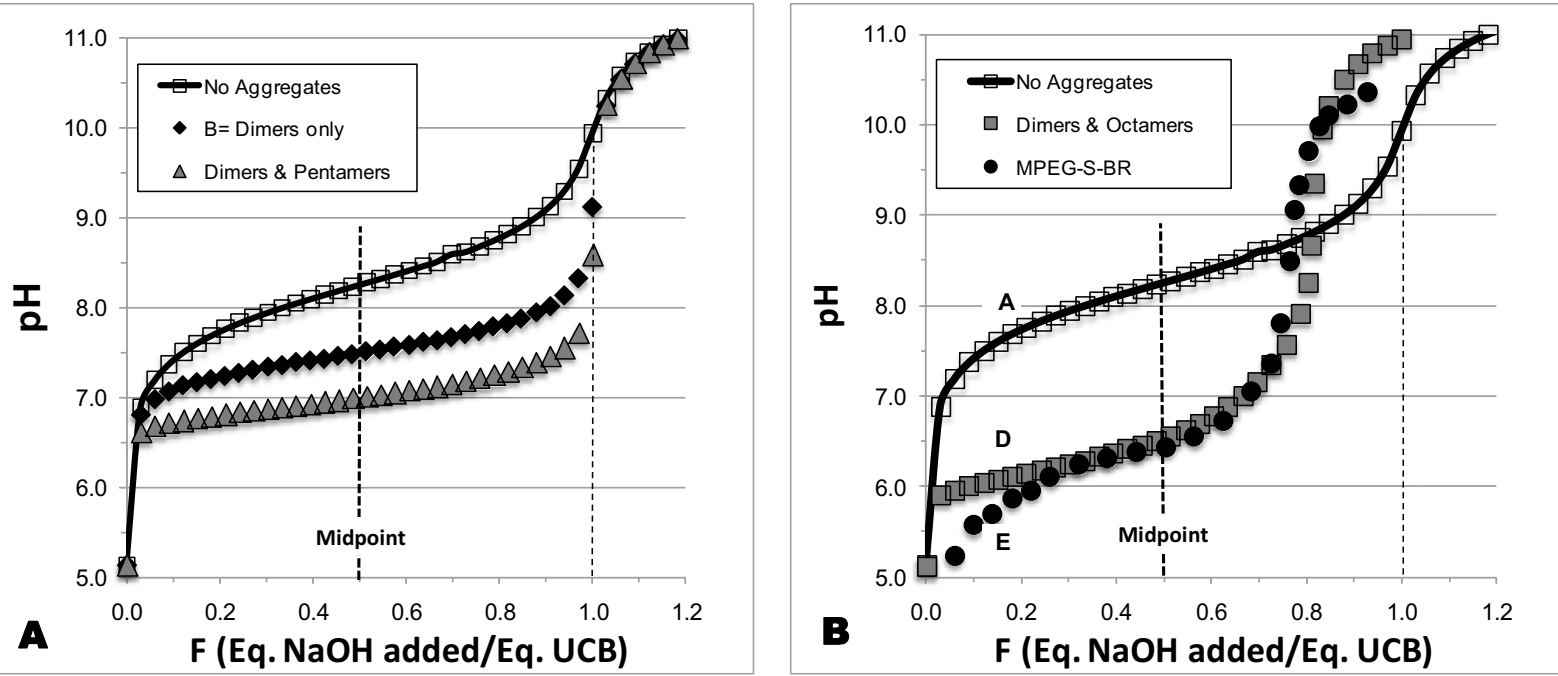

Figure 1 Influence of aggregates on the titration of $\mathrm{UCB}$ with $\mathrm{NaOH}$. Four models of changes in $\mathrm{pH}$ expected during titration of $25 \mathrm{ml}$ of $7 \mathrm{mM}$ UCB with $10.6 \mathrm{mM} \mathrm{NaOH}$, compared with the experimental titration curve of MPEG-S-BR [9]. pH values, calculated according Equations 5 and 6 in the Appendix, are plotted against $\mathrm{F}$, the ratio of the equivalents of added $\mathrm{NaOH}$ to the equivalents of MPEG-S-BR. Full neutralization corresponds to $\mathrm{F}=1$ (light dashed line) and the titration mid-point is at $F=0.5$ (heavy dashed line). The models apply our previously estimated constants for UCB [10] of $\mathrm{pK}_{1}=8.1, \mathrm{pK}_{2}=8.4$, and $\mathrm{K}_{\mathrm{D}}=2.6 \times 10^{5} \mathrm{M}^{-1}$, the formation constant of $(\mathrm{B}=)_{2}$, the dimer of the UCB dianion. The models considered below ignore the even higher multimers of $\mathrm{B}=$ and higher mixed aggregates of $\mathrm{HB}$ and $\mathrm{B}=$ that would be expected in the real system $[9,47]$. See Appendix for details. $\mathbf{A}$. Curve $A$ (open squares) assumes there is no self-association of any UCB species. Curve B (black diamonds) assumes the only aggregate is the dianion dimer, $(B=)_{2}$. Curve $C$ (gray triangles) assumes dimers and pentamers, the added pentamer species, $(B=)_{5}$, having a formation constant $K_{5}$, given by log $K_{5}=22.66$ for the equilibrium $5 B=(B=)_{5}$. B. Curve $D$ (gray squares) incorporates $\left(B^{=}\right)_{2}$, and three octamers, $\left(H^{+}\right)_{3}\left(B^{=}\right)_{8}\left(H^{+}\right)_{4}\left(B^{=}\right)_{8}$, and $\left(H^{+}\right)_{5}\left(B^{=}\right)_{8}$, which are mixed adducts of $\mathrm{HB}^{-}$and $B=$ with formation constants given by $\log \mathrm{K}=40,39$ and 38 , respectively. Curve $\mathrm{E}$ (black dots), the experimental potentiometric titration curve of MPEG-S-BR from Figure 2a of Boiadjiev et al. [9] (see text), is approximated by Curve D, but not by Curve A. The pH at the titration mid-point for each curve $(A, 8.26 ; B, 7.62 ; C, 6.99 ; D, 6.54)$ decreases as the size of the UCB aggregates increases, and is lowest for MPEG-S-BR $(\mathrm{E}, 6.42)$

would be expected. In Figure 1B, curve D, we show a model containing $\left(\mathrm{B}^{=}\right)_{2}$, and mixed aggregation of $\mathrm{HB}^{-}$ and $\mathrm{B}^{=}$to produce the octamers, $\left(\mathrm{H}^{+}\right)_{3}\left(\mathrm{~B}^{=}\right)_{8},\left(\mathrm{H}^{+}\right)_{4}\left(\mathrm{~B}^{=}\right)_{8}$ and $\left(\mathrm{H}^{+}\right)_{5}\left(\mathrm{~B}^{-}\right)_{8}$. As explained in the Appendix, we assume the formation constants of these aggregates to be given by $\log K=40,39$ and 38 respectively. When the three octameric species are added to the dimer, the calculated titration curve D shows some remarkable features that closely mimic the very peculiar characteristics of the published titration curve (E) for MPEG-S-BR [9]. For this curve, we assumed MPEG-S-BR to be pure and calculated $F$ values from the $\mathrm{mEq}$ of $\mathrm{NaOH}$ added to $0.400 \mathrm{mEq}$ of MPEG-SBR [9]. The steep increase in $\mathrm{pH}$ with added $\mathrm{NaOH}$ around $\mathrm{F}=0.80,20 \%$ below nominal neutralization is extraordinary and can easily lead to a premature endpoint assignment. It simulates the steep increase observed for MPEG-S-BR which leads to an assigned titration end-point about $24 \%$ below the nominal neutralization point. The $\mathrm{pH}$ changes in gentle fashion at around $\mathrm{F}=1$. The mid-point $\mathrm{pH}$ value is in the range of 6.5 to 6.6, depending upon how the titration end-point is chosen, close to the experimental value of 6.42 for MPEG-S-BR [9].

Our models for UCB, which include aggregates, thus provide some qualitative rationalization for the very unusual features of the titration curves for MPEG-S-BR [9]. The comparison is dependent upon the assumptions that: a) the bilirubin moiety in MPEG-S-BR behaves essentially like UCB [9]; b) the MPEG-S-BR used was reasonably pure; and c) the low equivalence value determined in the $\mathrm{NaOH}$ titration of MPEG-S-BR is due to premature identification of the end point. We emphasize that our models are based on the current limited understanding of the self-association of UCB, and can only be qualitative. It is clear, however, that, since all our models use pKa values of 8.1 and 8.4 for monomeric UCB, selfassociation leads to a reduction in the apparent average $\mathrm{pKa}$ values that are estimated from the $\mathrm{pH}$ at the midpoint of the titration. If the self-association behavior of MPEG-S-BR is similar to that of UCB, the reported average pKa of 6.4 for MPEG-S-BR, derived from the titration midpoint [9], must be lower than the true pKa values of monomeric MPEG-S-BR and is thus qualitatively incon- 
sistent with low pKa values for UCB. If MPEG-S-BR is not similar to UCB, no conclusions can be drawn regarding UCB. The extraordinary aspects of the modeled titration curves may also be of some usefulness in the understanding of the acid titrations of high concentrations of sodium salts of UCB [47].

In summary, we have pointed out the many experimental problems associated with the acid-base titration of MPEG-S-BR and MPEG-FAs [9], and serious dissimilarities of the titration curves of MPEG-FAs and MPEG-SBR. The former can be explained by classical electrostatic theories and are inappropriate models for the latter. In view of the very high concentrations of MPEG-S-BR used for titration, we have modeled the effects of self-aggregation of UCB on its titration curves and the apparent pKa of about 6.4, derived from the mid-point of the curve [9] (see appendix). Our modeling thus suggests that the pKa values of monomeric MPEG-S-BR may be similar to the high values of 8.1 and 8.4 for UCB. The data for MPEG-S$\mathrm{BR}$ clearly provide no acceptable evidence for low $\mathrm{pKa}$ values of monomeric UCB itself.

\section{Conclusions}

\section{Summary}

We have summarized estimates of bilirubin $\mathrm{pKa}$ values derived from published potentiometric or spectroscopic titrations, dissolution of UCB crystals, HNP measurements in DMF, co-titrations in DMSO coupled with the use of the Born equation, and the recent estimates from NMR data of $\left[{ }^{13} \mathrm{C}\right]$-mesobilirubin-XIII $\alpha$ in water$\left(\mathrm{CD}_{3}\right)_{2} \mathrm{SO}$ mixtures and the titration of MPEG-S-BR in water (Additional file 1, Table S1). We have shown all those estimates to be unreliable, due to failure to fulfill one or more of the minimum criteria for a valid study, as well as other serious deficiencies that confound interpretation of those studies. As summarized in Additional file 1 , Table S1, only our solvent partition studies $[10,11]$ have met all the requirements for valid experiments when using a poorly-soluble, unstable compound, such as UCB, and these studies clearly indicate that the $\mathrm{pKa}$ values of UCB are well above the mean pKa values of simple monoand di-carboxylic acids (below 5.0) [28,31]. We also note that a critical evaluation of the theoretical basis used in deriving aqueous $\mathrm{pKa}$ values in water from experiments in DMF [26] and DMSO $[27,29,37]$ reveals serious deficiencies. The new analysis gives rise to new pKa estimates: the average pKa of UCB in DMSO is about 11.1 and in DMF it is above 10. These values are consistent with the high pKa values of UCB in water [10,11]. Some models used to rationalize unusual titration behavior of MPEG-S-BR indicate an important general concept: reversible self-association of UCB-type molecules, involving primarily dianions, can lead to falsely low esti- mates of pKa values and can generate some unusual titration curves.

\section{Concluding remarks}

We first highlight the major factors involved in the reporting of low, intermediate and high $\mathrm{pKa}$ values for UCB. We have detailed many different reasons for deciding why most of the pKa values in Additional file 1, Table S1 are unreliable. A general point, applicable especially to the spectral studies in water (Additional file 1, Table S1), is that acidification of true solutions of UCB, initially dissolved at a high $\mathrm{pH}$, can cause massive supersaturation, followed by formation of colloidal and coarser species, which themselves cause spectral changes [33-35]. The net effects of these non-equilibrium processes may depend upon time, concentration, impurities and, most importantly, on how low the $\mathrm{pH}$ becomes. These variable factors, particularly the effects of $\mathrm{pH}$ on the formation of aggregates, largely explain the serious discrepancies among the various reported pKa values (Additional file 1, Table S1), as well as their relatively low magnitude (clearly illustrated in Figure 1).

Potentiometric titration has shown that most of the neutralization by added acids, of UCB dissolved at a high $\mathrm{pH}$, occurs between $\mathrm{pH} 8$ and 7 [35]. Leaving aside the two lowest of the extraordinary set of four pKa values reported by Kolosov and Shapolovenko [21], the average experimental $\mathrm{pKa}$ values from four spectrophotometric studies [20-23] and one potentiometric titration [24] (Additional file 1, Table S1) lie between 6.8 and 7.6. The average pKa values of 6.8 [22] and 8.1 [25], derived from dissolution of crystals of UCB diacid, are moderately high, but unacceptable for reasons described above and by Hahm, et al. [10]. The very low average pKa values of about 4.6, promulgated frequently in recent years, have been derived, directly or indirectly, mostly from studies in non-aqueous media [26-31], or using a water-soluble, thioether conjugate of UCB [9]. Their deficiencies have been detailed above and summarized in Additional file 1, Table S1. The high aqueous pKa values of $8.12 \pm 0.23$ and $8.44 \pm 0.33$ (mean \pm S.D.), that we have concluded to be reliable, derive from partition of UCB between aqueous solutions and chloroform [10,11]. Uniquely, these two studies were designed to avoid problems of supersaturation, precipitation and degradation of UCB during prolonged procedures.

\section{Rationale for and significance of high pKa values of UCB}

In our earlier papers $[1,10,25]$, the high $\mathrm{pKa}$ values of UCB were attributed to hydrogen-bonding interactions, without detailed rationalization. Our recent study, with $\left[{ }^{14} \mathrm{C}\right]-\mathrm{UCB}[11]$, confirmed our original solvent partition data using unlabeled UCB [10], and postulated three factors that, collectively, could explain the remarkably high 
pKa values of 8.12 and 8.44 derived from these experiments. Each factor was related to the crowded and constrained microenvironment created for each $-\mathrm{COOH}$ or ionized - $\mathrm{COO}^{-}$group in $\mathrm{UCB}$, by the unique, multiple intramolecular $\mathrm{H}$-bonds involving these groups [62]. These factors are [11]: a) donation of an $\mathrm{H}$-bond from the $-\mathrm{OH}$ moiety of the $-\mathrm{COOH}$ group; b) hindered solvation of the - $\mathrm{COO}^{-}$group; and c) restricted rotation of the $\mathrm{COO}^{-}$and $-\mathrm{COOH}$ groups, which also contributes to suboptimal solvation. The evidence for these effects on the suppressed ionization of the - $\mathrm{COOH}$ groups in UCB has been detailed elsewhere [11].

These theoretical rationalizations indicate that such remarkably high pKa values are not unreasonable [11], and dictate that the freely diffusible UCB diacid $\left(\mathrm{H}_{2} \mathrm{~B}\right)$ [1], rather than the dianion $\left(B^{=}\right)$[63], is the predominant unbound species of UCB in plasma at physiological $\mathrm{pH}$. The implications for understanding UCB cytotoxicity and bilirubin encephalopathy in jaundiced neonates have been discussed elsewhere $[3,64]$.

\section{Appendix}

\section{Simulation of the Effects of Self-Association on Titration Curves of UCB}

The titration curves in Figure 1 are represented by plots of $\mathrm{pH}$ vs. $\mathrm{F}$, where $\mathrm{F}$ is the ratio of equivalents of $\mathrm{NaOH}$ added to the total equivalents of UCB or MPEG-S-BR. The total concentration of UCB or MPEG-S-BR in solution is given by Equation 5 .

$$
\begin{aligned}
\mathrm{B}_{\mathrm{T}}= & {\left[\mathrm{H}_{2} \mathrm{~B}\right]+\left[\mathrm{HB}^{-}\right]+\left[\mathrm{B}^{=}\right]+2\left[\left(\mathrm{~B}^{=}\right)_{2}\right]+5\left[\left(\mathrm{~B}^{=}\right)_{5}\right] } \\
& +8\left[\left(\mathrm{H}^{+}\right)_{3}\left(\mathrm{~B}^{=}\right)_{8}\right]+8\left[\left(\mathrm{H}^{+}\right)_{4}\left(\mathrm{~B}^{=}\right)_{8}\right]+8\left[( \mathrm { H } ^ { + } ) _ { 5 } \left(\mathrm{~B}^{=}\right.\right.
\end{aligned}
$$

The particular model of aggregation chosen for simulation of the titration curve determines which of the above aggregates are selected for inclusion in Equation 5 (see below). The corresponding aggregate species must also be selected for Equation 6, which represents the concentration of $\mathrm{Na}^{+}$in the system.

$$
\begin{aligned}
{\left[\mathrm{Na}^{+}\right] } & =\left[\mathrm{HB}^{-}\right]+2\left[\mathrm{~B}^{=}\right]+4\left[\left(\mathrm{~B}^{=}\right)_{2}\right]+10\left[\left(\mathrm{~B}^{=}\right)_{5}\right] \\
& +13\left[\left(\mathrm{H}^{+}\right)_{3}\left(\mathrm{~B}^{=}\right)_{8}\right]+12\left[\left(\mathrm{H}^{+}\right)_{4}\left(\mathrm{~B}^{=}\right)_{8}\right]+11\left[\left(\mathrm{H}^{+}\right)_{5}\left(\mathrm{~B}^{=}\right)_{8}\right]+[\mathrm{OH}
\end{aligned}
$$

In Equations 5 and 6, all the terms on the right hand side can be represented by the equilibrium concentrations of $\left[\mathrm{B}^{-}\right]$and $\left[\mathrm{H}^{+}\right]$. The chosen values of $\mathrm{pK} 1=8.1$ and $\mathrm{pK} 2=8.4[10]$ and the $\mathrm{pKw}$ value of $10^{-14}$, can be used to calculate $\left[\mathrm{H}_{2} \mathrm{~B}\right],\left[\mathrm{HB}^{-}\right]$and $\left[\mathrm{OH}^{-}\right]$. The models assume that the role of the MPEG moiety is negligible, so that our previously estimated constants for UCB [10] also apply to MPEG-S-BR. The equilibria described below for the formation of aggregates allow their concentrations to be determined from the equilibrium values of $\left[\mathrm{HB}^{-}\right]+\left[\mathrm{B}^{=}\right]$ and, therefore, from $\left[\mathrm{B}^{-}\right]$and $\left[\mathrm{H}^{+}\right]$, using the equilibrium constants chosen for the simulations. Different known values of $\mathrm{BT}$ and $\left[\mathrm{Na}^{+}\right]$were generated in the progressive titration of $25 \mathrm{~mL}$ of $0.007 \mathrm{M} \mathrm{UCB}$ with $1.06 \times 10^{2} \mathrm{M}$ $\mathrm{NaOH}$, up to and beyond neutralization, taking volume changes into account. The concentrations chosen are similar to those used for titration of MPEG-S-BR with $\mathrm{NaOH}$ by Boiadjiev et al. [9]. Equations 5 and 6 were solved for the two unknowns, the equilibrium values $[\mathrm{B}=]$ and $\left[\mathrm{H}^{+}\right]$, using the SCIENTIST program (Micromath Scientific Software, Salt Lake City, UT). The equilibrium $\mathrm{pH}$ values so determined have been plotted against $\mathrm{F}$ in Figures $1 \mathrm{~A} \& \mathrm{~B}$, neutralization being represented by $\mathrm{F}=$ 1.

Four different models (A-D), with increasingly complex self-association patterns, have been examined to determine how some of the characteristic features of the titration are affected by self-association of $\left[\mathrm{B}^{=}\right]$. All concentrations were in $\mathrm{mol} / \mathrm{L}$ units, and the assumed equilibrium constants had, therefore, units consistent with this.

Model A - No aggregation of $\mathrm{B}=$ in Equations 1 and 2. $\mathrm{BT}=\left[\mathrm{H}_{2} \mathrm{~B}\right]+\left[\mathrm{HB}^{-}\right]+\left[\mathrm{B}^{=}\right]$.

Model $\mathrm{B}$ - The aggregation is limited to the dianion dimer, $\left(\mathrm{B}^{\mathrm{N}}\right)_{2}$, so that

$\mathrm{BT}=\left[\mathrm{H}_{2} \mathrm{~B}\right]+\left[\mathrm{HB}^{-}\right]+\left[\mathrm{B}^{=}\right]+2\left[\left(\mathrm{~B}^{=}\right)_{2}\right]$. The dimerization constant, $\mathrm{KD}$, for the equilibrium $2 \mathrm{~B}^{=} \quad\left(\mathrm{B}^{=}\right)_{2}$, has been estimated as $2.6 \times 10^{5} \mathrm{M}^{-1}$ [10] and $6.7 \times 10^{5} \mathrm{M}^{-1}$ [47]. We have chosen, conservatively, the lower value $(\log \mathrm{KD}=$ 5.415 , rather than 5.826).

Model C - We assume the formation of $(B=)_{2}$ and the pentameter, $\left(\mathrm{B}^{=}\right)_{5}$. Therefore, $\mathrm{BT}=\left[\mathrm{H}_{2} \mathrm{~B}\right]+\left[\mathrm{HB}^{-}\right]+\left[\mathrm{B}^{=}\right]+$ $2\left[\left(\mathrm{~B}^{=}\right)_{2}\right]+5\left[\left(\mathrm{~B}^{=}\right)_{5}\right]$. In the absence of any co-operativity, the value of $\mathrm{K} 5$, the equilibrium constant governing pentamer formation, $5 B^{=} \quad(B=)_{5}$, should be $(K D)^{4}$. Since some co-operativity is expected, we have used $\log \mathrm{K} 5=4 \log \mathrm{KD}$ $+1=22.66$, assuming $\mathrm{KD}$ has the lower value of $2.6 \times 10^{5}$ $\mathrm{M}^{-1}[10]$.

Model D - For larger aggregates, the formation of heteromers is likely [47]. In this model, we have assumed the presence of three mixed adducts of $\mathrm{HB}^{-}$and $\mathrm{B}^{=}$containing 8 monomers, $\left(\mathrm{H}^{+}\right)_{3}\left(\mathrm{~B}^{=}\right)_{8},\left(\mathrm{H}^{+}\right)_{4}\left(\mathrm{~B}^{=}\right)_{8}$, and $\left(\mathrm{H}^{+}\right)_{5}\left(\mathrm{~B}^{=}\right)_{8}$, along with the dimer, $\left(\mathrm{B}^{=}\right)_{2} \cdot \mathrm{B}_{\mathrm{T}}=\left[\mathrm{H}_{2} \mathrm{~B}\right]+\left[\mathrm{HB}^{-}\right]+\left[\mathrm{B}^{=}\right]+2\left[\left(\mathrm{~B}^{=}\right)_{2}\right]$ $+8\left[\left(\mathrm{H}^{+}\right)_{3}\left(\mathrm{~B}^{=}\right)_{8}\right]+8\left[\left(\mathrm{H}^{+}\right)_{4}\left(\mathrm{~B}^{=}\right)_{8}\right]+8\left[\left(\mathrm{H}^{+}\right)_{5}\left(\mathrm{~B}^{-}\right)_{8}\right]$

Significant co-operativity is expected in the formation of these larger species, but the self-association of HB- is expected to be less favorable than the self-association of $B=[10,47]$. If there is no co-operativity of self-association, and if $\mathrm{HB}^{-}$and $\mathrm{B}^{\mathrm{a}}$ exhibit the same tendency to self-associate, the $\mathrm{K}$ value controlling the formation of the octameric species from the monomeric species should be given by $(\mathrm{KD})^{7}$, so that $\log \mathrm{K}=37.9$ for the lower value of 
$\mathrm{KD}\left(2.6 \times 10^{5} \mathrm{M}^{-1}\right)[10]$ and $\log \mathrm{K}=40.8$ for the higher value of KD $\left(6.7 \times 10^{5} \mathrm{M}^{-1}\right)$ [47]. Co-operativity effects should increase $\log \mathrm{K}$ by a few units. To accommodate both effects, we have selected $\log \mathrm{K}\left(\mathrm{H}^{+}\right)_{3}\left(\mathrm{~B}^{=}\right)_{8}=40$ for the equilibrium $3 \mathrm{HB}^{-}+5 \mathrm{~B}^{=} \quad\left(\mathrm{H}^{+}\right)_{3}\left(\mathrm{~B}^{=}\right)_{8}, \log \mathrm{K}\left(\mathrm{H}^{+}\right)_{4}\left(\mathrm{~B}^{=}\right)_{8}=$ 39 for $4 \mathrm{HB}^{-}+4 \mathrm{~B}^{=} \quad\left(\mathrm{H}^{+}\right)_{4}\left(\mathrm{~B}^{=}\right)_{8}$, and $\log \mathrm{K}\left(\mathrm{H}^{+}\right)_{5}\left(\mathrm{~B}^{=}\right)_{8}=38$ for $5 \mathrm{HB}^{-}+3 \mathrm{~B}^{=} \quad\left(\mathrm{H}^{+}\right)_{5}\left(\mathrm{~B}^{-}\right)_{8}$. The log $\mathrm{K}$ values represent some contribution of co-operativity. The progressively lower $\mathrm{K}$ values in the sequence $\log \mathrm{K}\left(\mathrm{H}^{+}\right)_{3}\left(\mathrm{~B}^{=}\right)_{8}>\log$ $\mathrm{K}\left(\mathrm{H}^{+}\right)_{4}\left(\mathrm{~B}^{=}\right)_{8}>\log \mathrm{K}\left(\mathrm{H}^{+}\right)_{5}\left(\mathrm{~B}^{-}\right)_{8}$ represent the expected weaker association of $\mathrm{HB}^{-}$compared with $\mathrm{B}^{=}$. The increasing net charge of the aggregates which contain fewer $\mathrm{HB}^{-}$will tend to mitigate this effect somewhat.

The key results of these simulated titrations are given in the text and Figure 1.

\section{Additional material}

\section{Additional file 1 Derived pKa values of bilirubin in simple systems}

Details of the 18 studies from 17 publications that were considered, including the degrees of supersaturation with UCB, the analytical methods used, the apparent pKa values, the experimental problems, and the citation. Citation numbers correspond to those in the list of references in the manuscript.

\section{Abbreviations}

UCB: unconjugated bilirubin; $B_{T}$ : total UCB concentration; $\mathrm{H}$-bond: hydrogenbond; $\mathrm{H}_{2} \mathrm{~B}$ : UCB diacid; $\mathrm{HB}=$ : UCB monoanions; $\mathrm{B}=$ : UCB dianion; $\mathrm{R}$ : the UCB saturation ratio $=$ free $U C B$ concentration/estimated solubility of $U C B$ at a given $p H$; DMF: dimethyl formamide; HNP: half-neutralization potential; NMR: nuclear magnetic resonance; MPEG: polyethylene glycol monomethyl ether; MPEG-SBR: thioether conjugate of MPEG with UCB; MPEG-FA: monoester conjugate of MPEG with a dicarboxylic fatty acid; $\left(\mathrm{CD}_{3}\right)_{2} \mathrm{SO}$ : deuterated dimethylsulfoxide; $\mathrm{CDCl}_{3}$ : deuterated chloroform; PEG: polyethylene glycol; c.m.c.: critical micellar concentration.

\section{Authors' contributions}

Both authors were equally involved in the conceptualization and writing of this paper, and both have read and approved the initial and revised manuscript JDO performed the literature search and PM developed the mathematical models

\section{Author Details}

'School of Pharmacy, University of Wisconsin, 777 Highland Ave., Madison, Wl, 53705-2222 USA and 2GI/Hepatology Division, Department of Medicine, Box 356424, University of Washington School of Medicine, 1959 NE Pacific St., Seattle, WA 98195-6424, USA

\section{Received: 26 March 2009 Accepted: 29 March 2010}

Published: 29 March 2010

\section{References}

1. Ostrow JD, Mukerjee P, Tiribelli C: Structure and binding of unconjugated bilirubin: relevance for physiological and pathophysiological function. J Lipid Res 1994, 35:1715-1737.

2. Zucker SD, Gössling W, Hoppin AG: Unconjugated bilirubin exhibits spontaneous diffusion through model lipid bilayers and native hepatocyte membranes. J Biol Chem 1999, 274:10852-10862.

3. Ostrow JD, Pascolo L, Brites D, Tiribelli C: Molecular basis of bilirubininduced neurotoxicity. Trends Mol Med 2004, 10:65-70.

4. Brodersen R: Binding of bilirubin to albumin; implications for prevention of bilirubin encephalopathy in the newborn. CRC Crit Rev Clin Lab Sci 1979, 11:305-399.
5. Jacobsen J, Brodersen R: Albumin-bilirubin binding mechanism; kinetic and spectroscopic studies of binding of bilirubin and xanthobilirubic acid to human serum albumin. J Biol Chem 1983, 258:6319-6326.

6. Gössling W, Zucker SD: Role of apolipoprotein D in the transport of bilirubin in plasma. Am J Physiol Gastrointest Liver Physiol 2000, 279:G356-G365.

7. Brodersen R: Physical chemistry of bilirubin: Binding to macromolecules and membranes. In Bilirubin. Vol. 1: Chemistry Edited by: Heirwegh KPM, Brown SB. Boca Raton, FL: CRC Press; 1982:75-123.

8. Hahm JS, Mun GH, Lee HL, Eun CS, Park JY, Han DS, Choi HS, Ahn YH: [Interactions of unconjugated bilirubin with bile acid by rapid solvent partition]. Taehan Kan Hakhoe Chi 2002, 8:80-89.

9. Boiadjiev SE, Watters K, Wolf S, Lai BN, Welch WH, McDonagh AF, Lightner DA: pKa and aggregation of bilirubin: titrimetric and ultracentrifugation studies on water-soluble pegylated conjugates of bilirubin and fatty acids. Biochemistry 2004, 43:15617-15632.

10. Hahm JS, Ostrow JD, Mukerjee P, Celic L: Ionization and self-association of unconjugated bilirubin, determined by rapid solvent partition from chloroform, with further studies of bilirubin solubility. J Lipid Res 1992, 33:1123-1137

11. Ostrow JD, Mukerjee P: Revalidation and rationale for high pKa values of unconjugated bilirubin. BMC Biochemistry 2007, 8:7.

12. Mukerjee P, Ostrow JD, Tiribelli C: Low solubility of unconjugated bilirubin in dimethylsulfoxide - water systems: implications for $\mathrm{pK}_{a}$ determinations. BMC Biochemistry 2002, 3:17.

13. Blanckaert N, Heirwegh KPM: Analysis and preparation of bilirubins and biliverdins. In Bile Pigments and Jaundice; Molecular, Metabolic and Medical Aspects Edited by: Ostrow JD. New York: Marcel Dekker; 1986:31-79.

14. Manitto P, Monti D, Garbagnati E: pH dependence of the water solubility of bilirubin photoderivatives and its relevance to phototherapy. Pediatr Res 1984, 18:378-381.

15. Ostrow JD, Mukerjee P: Solvent partition of (14)C-unconjugated bilirubin to remove labeled polar contaminants. Trans/ Res 2007, 149:37-45.

16. Overbeek JTG, Vink CLJ, Deenstra H: The solubility of bilirubin. Rec Trav Chim Pays-Bas 1955, 74:81-84.

17. Mukerjee P, Ostrow JD: Interactions of unconjugated bilirubin with vesicles, cyclodextrins and micelles: New modeling and the role of high pKa values. BMC Biochemistry 2010, 11:15.

18. With TK: Biology of Bile Pigments Copenhagen: Arne Frost-Hansen; 1954

19. With TK: Bile Pigments: Chemical, Biological and Clinical Aspects New York: Academic Press; 1968.

20. Gray CH, Kulczyka A, Nicholson DC: The chemistry of the bile pigments. IV. Spectrophotometric titration of the bile pigments. J Chem Soc 1961:2276-2285

21. Kolosov IV, Shapolovenko EP: Acid-base equilibria in bilirubin solutions. Zh Obshch Khim (J Gen Chem, USSR) 1977, 47:2149-2151.

22. Moroi Y, Matuura R, Hisadome T: Bilirubin in aqueous solution. Absorption spectrum, aqueous solubility, and dissociation constants. Bull Chem Soc Jpn 1985, 58:1426-1431.

23. Russell MP, Coulthurst SJ, Moore JN, Hester RE: Resonance Raman study of the chromophore-specific vibrational and electronic spectra of bilirubin. JChem Soc Faraday Trans 1995, 91:1751-1757.

24. Krasner J, Yaffe SJ: The automatic titration of bilirubin. Biochem Med 1973, 7:128-134

25. Ostrow JD, Celic L, Mukerjee P: Molecular and micellar associations in the $\mathrm{pH}$-dependent stable and metastable dissolution of unconjugated bilirubin by bile salts. J Lipid Res 1988, 29:335-348.

26. Lee JJ, Daly LH, Cowger ML: Bilirubin ionic equilibria: their effects on spectra and on conformation. Res Commun Chem Pathol Pharmacol 1974, 9:763-770.

27. Hansen PE, Thiessen $\mathrm{H}$, Brodersen R: Bilirubin acidity. Titrimetric and ${ }^{13} \mathrm{C}$ NMR studies. Acta Chem Scand 1979, 33:281-293.

28. Holmes DL, Lightner DA: Synthesis and acidity constants of ${ }^{13} \mathrm{CO}_{2} \mathrm{H}-$ labelled dicarboxylic acids. $p K_{\mathrm{a}} \mathrm{s}$ from ${ }^{13} \mathrm{C}-\mathrm{NMR}$. Tetrahedron 1996, 52:5319-5338

29. Lightner DA, Holmes DL, McDonagh AF: On the acid dissociation constants of bilirubin and biliverdin. $\mathrm{p} K_{\mathrm{a}}$ values from ${ }^{13} \mathrm{C}$ NMR spectroscopy. J Biol Chem 1996, 271:2397-2405. 
30. Lightner DA, Holmes DL, MCDonagh AF: Dissociation constants of waterinsoluble carboxylic acids by ${ }^{13} \mathrm{C}-\mathrm{NMR} . \mathrm{p \textrm {K } _ { \mathrm { a } }}$ s of mesobiliverdin-XIII a and mesobilirubin-XIIIa. Experientia 1996, 51:639-642.

31. McDonagh AF, Phimster A, Boiadjiev SE, Lightner DA: Dissociation constants of carboxylic acids by ${ }^{13} \mathrm{C}-\mathrm{NMR}$ in DMSO/water. Tetrahedron Letters 1999, 40:8515-8518

32. Irollo R, Casteran M, Dang VB, Yonger J: [Study of bilirubin-albumin binding. I. In vitro study by partition of bilirubin between an aqueous solution and an immiscible organic solvent (author's transl)]. Ann Biol Clin (Paris) 1979, 37:331-342.

33. Brodersen $\mathrm{R}$, Theilgaard J: Bilirubin colloid formation in neutral aqueous solution. Scand J Clin Lab Invest 1969, 24:395-398.

34. Lee KS, Gartner LM: Spectrophotometric characteristics of bilirubin. Pediatr Res 1976, 10:782-788

35. Carey MC, Spivak W: Physical chemistry of bile pigments and porphyrins with particular reference to bile. In Bile Pigments and Jaundice; Molecular, Metabolic and Medical Aspects Edited by: Ostrow JD. New York: Marcel Dekker; 1986:81-132.

36. Vold RD, Vold MJ: Colloid and Interface Chemistry Reading, MA: AddisonWesley; 1983

37. Trull FR, Boiadjiev SE, Lightner DA, McDonagh AF: Aqueous dissociation constants of bile pigments and sparingly soluble carboxylic acids by ${ }^{13} \mathrm{C}$ NMR in aqueous dimethyl sulfoxide: effects of hydrogen bonding. J Lipid Res 1997, 38:1178-1188.

38. Lucassen J: The diazo reaction of bilirubin and bilirubin diglucuronide. (PhD Thesis, Univ. of Utrecht) Univ. Utrecht: Kemink en Zoon; 1961.

39. Streuli CA, Miron RR: Relative acidities of organic acids in pyridine and water. Anal Chem 1958, 30:1978-1983.

40. Kolthoff IM, Chantooni MKJr: Substituent effects on dissociation of benzoic acids and heteroconjugation of benzoates with $p$ bromophenol in acetonitrile, $\mathrm{N}, \mathrm{N}$-dimethylformamide and dimethyl sulfoxide. Intramolecular hydrogen bonding in o-hydroxybenzoic acids and their anions. J Am Chem Soc 1971, 93:3843-3849.

41. Kolthoff IM, Chantooni MK Jr: General introduction to acid-base equilibria in nonaqueous organic solvents. In Treatise on Analytical Chemistry Edited by: Kolthoff IM, Elving PJ. New York: John Wiley \& Sons; 1979:239-302

42. Mukerjee P, Ostrow JD: Effects of added dimethylsulfoxide on pKa values of uncharged organic acids and $\mathrm{pH}$ values of aqueous buffers. Tetrahedron Letters 1998, 39:423-426.

43. Reichardt C: Solvents and Solvent Effects in Organic Chemistry 3rd edition. Weinheim, Germany: Wiley-VCH; 2003.

44. Kolthoff IM, Chantooni MK Jr, Bhowmik S: Dissociation constants of uncharged and monovalent cation acids in dimethyl sulfoxide. J Am Chem Soc 1968, 90:23-28.

45. Riddick JA, Bunger WB, Sakano TK: Organic Solvents: Physical Properties and Methods of Purification 4th edition. New York: Wiley-Interscience; 1986.

46. Brodersen R, Vind I: Chloroform extraction of serum bilirubin in relation to its binding to proteins. Scand J Clin Lab Invest 1963, 15:107-114.

47. Carey MC, Koretsky AP: Self association of unconjugated bilirubin IXa in aqueous solution at $\mathrm{pH} 10.0$ and physico-chemical interactions with bile salt monomers and micelles. Biochem J 1979, 179:675-689.

48. Mukerjee P: Micellar properties of drugs: micellar and nonmicellar patterns of self-association of hydrophobic solutes of different molecular structures - Monomer fraction, availability, and misuses of micellar hypothesis. J Pharm Sci 1974, 63:974-981.

49. Mukerjee P, Cardinal JR: Solubilization as a method for studying selfassociation: solubility of naphthalene in the bile salt sodium cholate and the complex pattern of its aggregation. J Pharm Sci 1976, 65:882-886

50. Mukerjee $P$, Moroi $Y$, Murata M, Yang AYS: Bile salts as atypical surfactants and solubilizers. Hepatology 1984, 4:61S-65S.

51. Mukerjee P, Cardinal JR, Desai NR: The nature of local microenvironments in aqueous micellar systems. In Micellization, Solubilization and Microemulsions Volume I. Edited by: Mittal KL. New York: Plenum; 1977:241-261.

52. Mukerjee P, Mysels KJ: Critical Micelle Concentrations of Aqueous Surfactant Systems (Pamphlet). Washington, DC, U.S. Government Printing Office; 1971.

53. Mukerjee P, Ghosh AK: "Isoextraction" method and the study of the selfassociation of methylene blue in aqueous solution. J Am Chem Soc 1970, 92:6403-6407.
54. Ghosh AK, Mukerjee P: Multiple association equilibria in the selfassociation of methylene blue and other dyes. J Am Chem Soc 1970, 92:6408-6412

55. Falk H: Molecular structure of bile pigments. In Bile Pigments and Jaundice; Molecular, Metabolic and Medical Aspects Edited by: Ostrow JD. New York: Marcel Dekker; 1986:7-27.

56. Ostrow JD, Celic L, Webster CC, Mukerjee P: Binding of unconjugated bilirubin (UCB) to various bile salts at $\mathrm{pH} 9.0$, assessed by solvent partition from $\mathrm{CHCl}_{3}$ [Abstract] Gastroenterology. 1994, 104:A968

57. Kurtin WE, Enz J, Dunsmoor C, Evans N, Lightner DA: Acid dissociation constants of bilirubin and related carboxylic acid compounds in bile salt solutions. Arch Biochem Biophys 2000, 381:83-91.

58. Maeder C, Beaudoin GM III, Hsu E, Escobar VA, Chambers SM, Kurtin WE, et al: Measurement of bilirubin partition coefficients in bile salt micelle/ aqueous buffer solutions by micellar electrokinetic chromatography. Electrophoresis 2000, 21:706-714

59. Mukerjee P, Banerjee K: A study of the surface $\mathrm{pH}$ of micelles using solubilized indicator dyes. J Phys Chem 1964, 68:3567-3574.

60. Adamson AW: Physical Chemistry of Surfaces 2 nd edition. New York: Interscience; 1967.

61. Huisman HF: Light scattering of solutions of ionic detergents III. Prock Ned Akad Wet Ser B, Physical Chem 1964, 67:388-406

62. Nogales $D$, Lightner DA: On the structure of bilirubin in solution; ${ }^{13} \mathrm{C}\left({ }^{1} \mathrm{H}\right)$ heteronuclear Overhauser effect NMR analysis in aqueous buffer and organic solvents. J Biol Chem 1995, 270:73-77.

63. Brodersen R: Bilirubin: solubility and interaction with albumin and phospholipid. J Biol Chem 1979, 254:2364-2369.

64. Ostrow JD, Pascolo L, Shapiro SM, Tiribelli C: New concepts in bilirubin encephalopathy. Eur J Clin Invest 2003, 33:988-997.

doi: $10.1186 / 1471-2091-11-15$

Cite this article as: Mukerjee and Ostrow, Review: Bilirubin pKa studies; new models and theories indicate high pKa values in water, dimethylformamide and DMSO BMC Biochemistry 2010, 11:15

\section{Submit your next manuscript to BioMed Centra and take full advantage of:}

- Convenient online submission

- Thorough peer review

- No space constraints or color figure charges

- Immediate publication on acceptance

- Inclusion in PubMed, CAS, Scopus and Google Scholar

- Research which is freely available for redistribution 